\title{
Early use of continuous positive airway pressure in the treatment of moderate to severe acute lower respiratory tract infections among patients younger than 2 years old
}

\author{
Laura Figueroa, M.D. ${ }^{a}$ and Federico Laffaye, M.D. ${ }^{a}$
}

\begin{abstract}
Objective. To analyze the characteristics of patients younger than 2 years old who had a moderate to severe acute lower respiratory tract infection and were treated early with bubble continuous positive airway pressure, and factors associated with a successful intervention.

Method. Retrospective and descriptive study. Children younger than 2 years old admitted to the Pediatric Intermediate Care Unit of Hospital Provincial Neuquén between June 2009 and December 2010. Bubble continuous positive airway pressure was used, and the following outcomes were measured: heart rate, respiratory rate, Tal's score, oxygen saturation, and fraction of inspired oxygen at $0,2,6,24$, and $48 \mathrm{~h}$.

Results. One hundred and twenty patients were included. Their median age was 3 months old.

The intervention was successful in $72 \%$ of patients. At $2 \mathrm{~h}$, a $15 \%$ reduction in respiratory rate, and a 2-point decrease in Tal's score were predictors of success, with an odds ratio of 6.41 (95\% confidence interval: 2.68-15.36), and of 9.07 (95\% confidence interval: 3.72-22.19), respectively.

Conclusions. A reduction in respiratory rate, heart rate, and Tal's score at 2 hours of starting theintervention were predictors of success.

Key words: bubble CPAP, bronchiolitis, pneumonia, children.
\end{abstract}

http:/ / dx.doi.org/10.5546/ aap.2017.eng.277

To cite: Figueroa L, Laffaye F. Early use of continuous positive airway pressure in the treatment of moderate to severe acute lower respiratory tract infections among patients younger than 2 years old. Arch Argent Pediatr 2017;115(3):277-281.

\section{INTRODUCTION}

Acute lower respiratory tract infections (ALRTIs) are an important cause of morbidity and mortality in our setting. ${ }^{1}$

a. Pediatric Intermediate Care Unit. Hospital Provincial Neuquén “Dr. E. Castro Rendón”.

E-mail address:

Laura Figueroa, M.D.: lauritafigueroa@yahoo.com.ar

Funding: None.

Conflict of interest: None.

Received: 5-9-2016

Accepted: 12-26-2016
The main clinical conditions included under the definition of ALRTI are bronchiolitis and pneumonia, which have a greater impact on childhood mortality, ${ }^{2}$ and set the basis for this study.

Non-invasive ventilation is an alternative for patients with moderate to severe ALRTIs. ${ }^{3-6}$ Different publications have mentioned a reduction in the length of hospital stay and a lower proportion of failure (less than $30 \%$ ), defined as the need for endotracheal intubation. ${ }^{7}$

The objective of this study was to analyze the characteristics of patients younger than 2 years old who had a moderate to severe ALRTI and treated early with bubble continuous positive airway pressure (CPAP), and factors associated with a successful intervention.

\section{POPULATION AND METHODS}

Retrospective and descriptive study. Children younger than 2 years old hospitalized between June 2009 and December 2010. Bubble CPAP was used, and the following outcomes were measured: heart rate (HR), respiratory rate (RR), Tal's score, oxygen saturation, and fraction of inspired oxygen $\left(\mathrm{FiO}_{2}\right)$ at $0,2,6,24$, and $48 \mathrm{~h}$.

Inclusion criteria for the use of bubble CPAP were as follows:

- Age between 1 and 24 months old.

- Weight $<12 \mathrm{~kg}$.

- Tal's score $>5$ points.

- Admission to the pediatric intermediate care unit.

Exclusion criteria were the following:

- Cardiorespiratory arrest.

- Hemodynamic instability in spite of intravenous treatment with volume expanders.

- Inotrope requirement.

- Absence of gag and/or cough reflex.

Collaborators:

Mario González, Germán Kaltenbach, Viviana Arias y Eugenia Cerda. 
Bubble CPAP consists of an interface (nasal cannula), inspiratory tubing, and expiratory tubing immersed in an underwater bottle system. The patient breaths spontaneously with positive pressure air flow, during both inspiration and expiration. Thus, continuous positive airway pressure is maintained throughout the breathing cycle.

CPAP includes an oxygen blender connected to a source of oxygen and compressed air used to supply an appropriate concentration of inspired oxygen $\left(\mathrm{FiO}_{2}\right)$. The humidified blended oxygen is then circulated through corrugated tubing. $\mathrm{FiO}_{2}$ is estimated based on the liters of air and oxygen delivered. Blended oxygen is delivered via a nasal cannula, and pressure in the circuit is maintained by immersing the distal end of the expiratory tubing in water. The depth to which the tubing is immersed underwater determines the pressure generated in the patient's airways (Figure 1).

Prior to placing the nasal interface, airway secretions were cleared and, if deemed convenient, a dose of sedative was given (chloral hydrate or benzodiazepines).
The Hudson RCI CPAP Cannula System (USA), sizes 1-5, was used. Bubble CPAP was first connected at $5 \mathrm{~cm} \mathrm{H}_{2} \mathrm{O}$ and, eventually, this level was progressively increased up to $8 \mathrm{~cm}$ $\mathrm{H}_{2} \mathrm{O}$, although a higher initial pressure could be used at the discretion of the treating physician. In addition, initial $\mathrm{FiO}_{2}$ was $100 \%$ and then reduced based on the patient's saturation.

Comorbidities were recorded: congenital heart disease, prematurity, malnutrition, bronchopulmonary dysplasia, and high social risk (unmet basic needs).

The presence of complications, such as abdominal distension, pressure injury, and pneumothorax, was determined.

In addition, patients' weight, age, sex, diagnosis, virological tests (indirect immunofluorescence assay [iIFA], polymerase chain reaction $[P C R])$, culture results, sedative administration, length of bubble CPAP use, and length of stay in the pediatric intensive care unit (PICU) were recorded.

CPAP was considered successful if the RR reduced by $15 \%$ from the previous value and

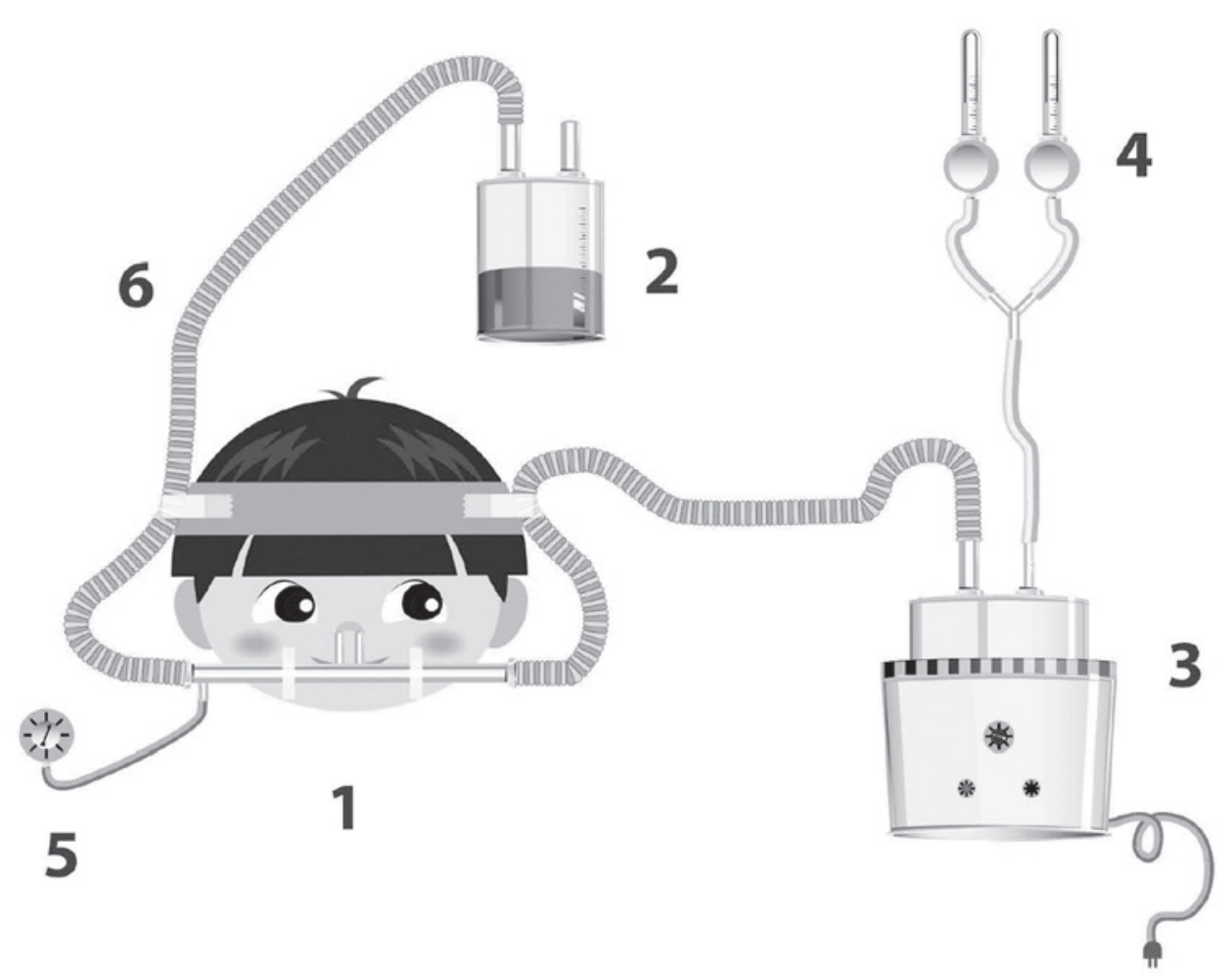

1. Nasal prongs. 2. Underwater bottle. 3. Heater. 4. Air-oxygen source. 5. Pressure gauge. 6. Expiratory tubing. 
Tal's score decreased by 2 points. CPAP was considered to fail if Tal's score did not reduce (HR, RR, intercostal retraction, wheezing) and/or desaturation $(<90 \%)$ and/or sensory deficit occurred, at the discretion of the treating physician.

Criteria to remove bubble CPAP were as follows: $\mathrm{CPAP}$ at $4 \mathrm{~cm} \mathrm{H}_{2} \mathrm{O}, \mathrm{FiO}_{2}<40 \%$, Tal's score of 4 points.

Simple descriptive statistics were used to describe the sample: mean, median, standard deviation (SD), and range. Percentages corresponding to qualitative outcome measures were estimated and compared using a $\chi^{2}$ test for independence to establish the association among outcome measures, with a significance level $<5 \%$. Odds ratios (ORs) were analyzed for all possible cases. In addition, box-and-whisker plots were used to describe how quantitative outcome measures behaved.

Sensitivity and specificity curves were used to establish cut-off points for bubble CPAP failure predictive outcome measures. Receiver operating characteristic (ROC) curves and their corresponding tests were used to establish which outcome measures worked better to determine bubble CPAP failure.

The study protocol was assessed and approved by the Advisory Commission for Biomedical Research in Humans (Comisión Asesora en Investigación Biomédica en Seres Humanos, CAIBSH).

\section{RESULTS}

One hundred and twenty patients were included. The intervention was successful in $72 \%$ of cases, and failed in $28 \%$.

Table 1 describes the demographic and clinical outcome measures of enrolled patients before CPAP use and compares successful and failed interventions.

All patients had an indirect immunofluorescence assay (IIFA), and respiratory syncytial virus (RSV) was detected in 70 cases. H1N1 was detected in $5 \%$ of patients.

CPAP was established at 5-8 $\mathrm{cm} \mathrm{H}_{2} \mathrm{O}$, with an average of $6 \mathrm{~cm} \mathrm{H}_{2} \mathrm{O}$.

Complications were observed in 3.3\% of cases (abdominal distension, pneumothorax).

Mean bubble CPAP duration was $74.93 \mathrm{~h}(95 \%$ confidence interval [CI]: 65.22-84.65).

Mean length of stay in the intermediate care unit was 10 days (95\% CI: 9.11-10.91); in the success group, it was 8.33 days (SD 3.36), and in the failure group, it was 14.93 days (SD 5.19) (the latter included the length of stay in the intensive care unit).

Table 2 shows outcome measures recorded during the hours after initiating bubble CPAP.

The subsequent analysis identified that a 15\% reduction in HR and a 2-point decrease in Tal's score at 2 hours of non-invasive ventilation (NIV) initiation were the factors related to success, with an OR of 6.41 (95\% CI: 2.68-15.36), and of 9.07 (95\% CI: 3.72-22.19), respectively.

TABLE 1. Baseline characteristics of the sample and each group as per CPAP success or failure. Age is stated as median and range; the other outcome measures, as mean \pm standard deviation

\begin{tabular}{|c|c|c|c|c|}
\hline & All $(n=120)$ & Success group $(n=86)$ & Failure group $(n=34)$ & $p$ \\
\hline Age (months old); X (range) & $3(1-22)$ & $6.08(2.3-12.45)$ & $5.4(2.9-12)$ & $>0.05$ \\
\hline Female & 65 & 41 & 24 & \\
\hline Weight (kg) & $6.49 \pm 2.24$ & $6.55 \pm 2.17$ & $6.35 \pm 2.43$ & \\
\hline Baseline RR & $68.75 \pm 12.71$ & $67.57 \pm 12.61$ & $71.74 \pm 12.65$ & \\
\hline Baseline HR & $167.14 \pm 23.05$ & $164.42 \pm 23.71$ & $174.03 \pm 19.99$ & \\
\hline Baseline $\mathrm{FiO}_{2}(\%)$ & $89.98 \pm 3.13$ & $89.74 \pm 3.36$ & $90.59 \pm 2.39$ & \\
\hline Oxygen saturation & $97.39 \pm 4.09$ & $97.42 \pm 4.53$ & $97.32 \pm 2.69$ & \\
\hline Tal's score & $9.26 \pm 1.79$ & $9.17 \pm 1.98$ & $9.47 \pm 1.19$ & \\
\hline Bronchiolitis & 55 & 42 & 13 & \\
\hline Pneumonia & 65 & 44 & 21 & \\
\hline \multicolumn{5}{|l|}{ Predisposing clinical condition } \\
\hline Prematurity & $29(24 \%)$ & $23(79 \%)$ & $6(21 \%)$ & $>0.05$ \\
\hline Malnutrition & $11(9.16 \%)$ & $8(73 \%)$ & $3(27 \%)$ & \\
\hline Bronchopulmonary dysplasia & $6(5 \%)$ & $5(83 \%)$ & $1(17 \%)$ & \\
\hline Congenital heart disease & $8(7 \%)$ & $5(62.5 \%)$ & $3(37.5 \%)$ & \\
\hline High social risk & $14(12 \%)$ & $8(57 \%)$ & $6(43 \%)$ & \\
\hline
\end{tabular}

RR: respiratory rate; $\mathrm{HR}$ : heart rate; $\mathrm{FiO} 2$ : fraction of inspired oxygen. 
When two qualitative outcome measures are combined, i.e., a 15\% reduction in RR and a 2-point decrease in Tal's score at 2 hours, OR increased to 13.31 (95\% CI: 4.51-39.26).

No statistically significant findings were made at 24 and $48 \mathrm{~h}$.

\section{DISCUSSION}

In our study, we described bubble CPAP use among patients younger than 2 years old with ALRTIs as a treatment strategy to avoid conventional mechanical ventilation.

The intervention was successful in $72 \%$ of cases, and failed in $28 \%$. Success percentage was similar to that published by other authors $(83 \%$ and $75.5 \%)^{8,9}$

In this study, at 2 hours of NIV initiation with bubble CPAP, a 15\% reduction in RR from the previous value and a 2-point decrease in Tal's score were predictors of success.

Other authors have also identified a reduction in RR as a predictor of NIV success. ${ }^{6}$ This fact highlights the importance of monitoring clinical parameters and ongoing assessment of these patients.

Unlike other studies, ${ }^{8-11} \mathrm{Tal}^{\prime} \mathrm{s}$ score was used in this study.
Modified Tal's score has demonstrated to be highly useful in practice for a standardization of clinical management and decision-making. ${ }^{12}$

Although HR significantly reduced at 2 hours, this outcome measure was an adequate predictor of failure as of $6 \mathrm{~h}$, unlike what has been reported by Mayordomo-Colunga et al., ${ }^{8}$ who mentioned that HR reduction in the first hour was an adequate predictor of success.

In this study, no statistically significant differences were observed between both groups in terms of weight, age, predisposing factors, or bronchiolitis or pneumonia diagnosis. Mayordomo-Colunga et al. indicated that the presence of apnea, a lower weight, and a younger age were predictors of failure, ${ }^{8}$ as well as Antonelli et al., ${ }^{9}$ who also identified a younger age, a higher Woods' score, acute respiratory distress syndrome (ARDS) or pneumonia.

In our experience, NIV given through bubble CPAP was a highly successful intervention among children with moderate to severe ALRTIs.

\section{CONCLUSION}

The early use of bubble CPAP works as a strategy to optimize patients' access to quality care and the utilization of available resources.

TABLE 2. Results. Respiratory rate, heart, rate, $\mathrm{FiO}_{2}$, oxygen saturation, and Tal's score

\begin{tabular}{|c|c|c|c|c|c|c|c|}
\hline \multirow{2}{*}{$\begin{array}{l}\text { Outcome } \\
\text { measure }\end{array}$} & \multicolumn{2}{|c|}{ Overall sample } & \multicolumn{2}{|c|}{ Success group } & \multicolumn{2}{|c|}{ Failure group } & \multirow[t]{2}{*}{$p$} \\
\hline & $\mathbf{n}$ & $X \pm S D$ & $\mathbf{n}$ & $\mathrm{X} \pm \mathrm{SD}$ & $\mathbf{n}$ & $\mathrm{X} \pm \mathrm{SD}$ & \\
\hline RR 2 & 120 & 55.7913 .67 & 86 & $51.78 \pm 11.3$ & 34 & $65.94 \pm 14.03$ & $<0.0001$ \\
\hline RR 6 & 114 & $55.72 \pm 13.9$ & 86 & $53.27 \pm 12.3$ & 28 & $63.25 \pm 15.94$ & 0.0008 \\
\hline RR 24 & 93 & $50.62 \pm 9 . .61$ & 86 & $50.17 \pm 9.4$ & 7 & $56.14 \pm 11.14$ & 0.1145 \\
\hline RR 48 & 84 & $48.73 \pm 10.21$ & 79 & $48.06 \pm 9.74$ & 5 & $59.20 \pm 13.01$ & 0.0171 \\
\hline HR 2 & 120 & $142.22 \pm 19.68$ & 86 & $139.06 \pm 18.01$ & 34 & $150.21 \pm 21.66$ & 0.0047 \\
\hline HR 6 & 114 & $140.46 \pm 19.37$ & 86 & $136.79 \pm 17.25$ & 28 & $151.75 \pm 21.40$ & 0.0003 \\
\hline HR 24 & 93 & $133.39 \pm 19.21$ & 86 & $132.84 \pm 19.38$ & 7 & $140.14 \pm 16.61$ & 0.3359 \\
\hline HR 48 & 84 & $127.42 \pm 21.98$ & 79 & $126.81 \pm 22.02$ & 5 & $137.00 \pm 21.12$ & 0.3177 \\
\hline $\mathrm{FiO}_{2} 2$ & 120 & $98.78 \pm 1.54$ & 86 & $98.95 \pm 1.37$ & 34 & $98.35 \pm 1.86$ & 0.0936 \\
\hline $\mathrm{FiO}_{2} 6$ & 115 & $98.89 \pm 1.63$ & 86 & $99.06 \pm 1.38$ & 29 & $98.38 \pm 2.18$ & 0.1238 \\
\hline $\mathrm{FiO}_{2} 24$ & 90 & $98.88 \pm 1.38$ & 82 & $98.93 \pm 1.34$ & 8 & $98.38 \pm 1.77$ & 0.2831 \\
\hline $\mathrm{FiO}_{2} 48$ & 83 & $98.36 \pm 2.14$ & 77 & $98.62 \pm 1.81$ & 6 & $95.00 \pm 3.35$ & 0.0470 \\
\hline Sat 2 & 119 & $86.5 \pm 15.26$ & 86 & $85.15 \pm 15.28$ & 33 & $90.03 \pm 14.85$ & 0.1188 \\
\hline Sat 6 & 114 & $82.73 \pm 17.66$ & 86 & $80.56 \pm 18.02$ & 28 & $89.39 \pm 14.92$ & 0.0208 \\
\hline Sat 24 & 87 & $72.26 \pm 18.32$ & 81 & $71.59 \pm 18.38$ & 6 & $81.33 \pm 16.08$ & 0.2108 \\
\hline Sat 48 & 80 & $66.25 \pm 16.93$ & 75 & $65.36 \pm 16.47$ & 5 & $79.6 \pm 20.02$ & 0.0682 \\
\hline Tal 2 & 120 & $6.08 \pm 2.02$ & 86 & $5.43 \pm 1.76$ & 34 & $7.74 \pm 1.69$ & $<0.0001$ \\
\hline Tal 6 & 114 & $5.54 \pm 1.83$ & 86 & $4.94 \pm 1.34$ & 28 & $7.39 \pm 1.91$ & $<0.0001$ \\
\hline
\end{tabular}

SD: standard deviation; RR: respiratory rate; HR: heart rate; FiO2: fraction of inspired oxygen; Sat: oxygen saturation; Tal: Tal's score; h: hours since non-invasive ventilation initiation. 
In this study, RR, HR at 2 hours, and Tal's score at 2 and 6 hours after NIV initiation were predictors of the success or failure of the intervention.

\section{REFERENCES}

1. Ministerio de Salud de la Nación. Estadísticas Vitales. [Accessed on: January $9^{\text {th }}, 2017$ ]. Available at: http:/ / www. deis.msal.gov.ar/index.php/estadisticasvitales/.

2. Comité Nacional de Neumología, Comité Nacional de Infectología, Comité Nacional de Medicina Interna. Recomendaciones para el manejo de las infecciones respiratorias agudas bajas (IRAB) en menores de 2 años. Arch Argent Pediatr 2015;113(4):373-4.

3. Fortenberry JD, Del Toro J, Jefferson LS, Evey L, et al. Management of pediatric acute hypoxemic respiratory insufficiency with bilevel positive pressure (BiPAP) nasal mask ventilation. Chest 1995;108(4):1059-64.

4. Teague WG. Noninvasive ventilation in the pediatric intensive care unit for children with acute respiratory failure. Pediatr Pilmonol 2003;35(6):418-26.

5. Medina Villanueva A, Prieto Espuñes S, Los Arcos Solas M, Rey Galán M, et al. Aplicación de la ventilación no invasiva en una unidad de cuidados intensivos pediátricos.
An Pediatr (Barc) 2005;62(1):13-9.

6. Essouri S, Chevret l, Durand P, Haas V, et al. Noninvasive positive pressure ventilation: five years of experience in a pediatric intensive care unit. Pediatr Crit Care Med 2006;7(6):329-34.

7. Bernet V, Hug MI, Frey B. Predictive factors for the success of noninvasive mask ventilation in infants and children with acute respiratory failure. Pediatr Crit Care Med 2005; 6(6):660-4.

8. Mayordomo-Colunga J, Medina A, Rey C, Los Arcos M, et al. Predictores de éxito y de fracaso en la ventilación no invasiva en la bornquiolitis aguda. An Pediatr (Barc) 2009;708(1):34-9.

9. Larrar S, Essouri S, Durand P, Chevret L, et al. Place de la ventilation non invasive nasale dans la prise en charge des broncho-alvéolites sévéres. Arch Pediatr 2006;13(11):1397-403.

10. JavouheyE, Barats A, Richard N,StammD, etal.Non-invasive ventilation as primary ventilatory support for infants with severe bronchiolitis. Intensive Care Med 2008;34(9):1608-14.

11. Antonelli M, Conti G, Moro M, Esquinas A, et al. Predictors of failure of noninvasive positive pressure ventilation in patients with acute hypoxemic respiratory failure: a multicenter study. Intensive Care Med 2001;27(11):1718-28.

12. Tal A, Bavilski C, Yohai D, Bearman J, et al. Dexamethasone and salbutamol in the treatment of acute wheezing in infants. Pediatrics 1983;71(1):13-8. 